\title{
Differences in metastatic patterns in relation to time between primary surgery and first relapse from breast cancer suggest synchronized growth of dormant micrometastases
}

\author{
Hanna Dillekås • Monica Transeth • \\ Martin Pilskog • Jörg Assmus • Oddbjørn Straume
}

Received: 20 May 2014 / Accepted: 7 July 2014/Published online: 20 July 2014

(C) The Author(s) 2014. This article is published with open access at Springerlink.com

\begin{abstract}
A significant variation in the metastatic pattern among breast cancer patients exists. Clinical observations suggest that these differences are related to time to recurrence (TTR), thus suggesting a common systemic growth signal at the time of surgery. Our goal was to identify a marker for synchronized growth of micrometastases. To quantify the metastatic pattern at first relapse, 180 patients with metastatic breast cancer were studied. Standard deviation (SD) of lesions size and lesion number was calculated and served as a marker for variation. Patients with low SD (multiple/similar sized lesions) were assumed to have synchronized growth, whereas patients with high SD were assumed to have unsynchronized growth. Patients were grouped according to TTR; early ( $<3$ years-) or late ( $>3$ years- after surgery). In patients not receiving systemic adjuvant treatment, median SD was significantly lower in the early group $(2.5 \mathrm{~mm})$ compared with $6.4 \mathrm{~mm}$ in the late group $(p=0.005)$. In node negative patients, median SD was significantly lower in the early group $(3.0 \mathrm{~mm})$ when compared with the late group $(5.7 \mathrm{~mm}$,
\end{abstract}

H. Dillekås · M. Transeth · M. Pilskog · O. Straume $(\bowtie)$ Department of Oncology, Haukeland University Hospital, 5021 Bergen, Norway

e-mail: oddbjorn.straume@ @else-bergen.no

J. Assmus

Centre for Clinical Research, Haukeland University Hospital,

Bergen, Norway

O. Straume

Department of Clinical Science, University of Bergen,

5012 Bergen, Norway

O. Straume

Centre of Cancer Biomarkers, University of Bergen,

5012 Bergen, Norway $p=0.02)$. An additional drop in SD was observed immediately after end of adjuvant endocrine therapy. Our results identify SD as a marker of synchronized metastatic growth in breast cancer. A metastatic phenotype characterized by multiple similar sized metastases, suggesting synchronized onset of growth of micrometastases was predominantly found in patients recurring early after surgery and was counteracted by adjuvant treatment. Systemic growth signals caused by surgery might be antagonized during the time window following surgery.

Keywords Breast cancer - Surgery - First relapse · Metastases · Radiology - Adjuvant treatment - Metastatic pattern · Tumor dormancy

\section{Introduction}

Breast cancer has a long natural history and is infamous for its propensity for late relapses when compared with most other cancer types [1]. Even clinically undetectable, tiny tumors can shed malignant cells into the circulation. Several biomarkers like ER, Her2, TNM-classification, and gene expression signatures [2-5] can readily be applied to predict early local or early distant disease recurrence within 5 years of diagnosis. On the other hand, no biomarkers have been proven clinically useful to predict late relapse [6, 7]. In cases with delayed relapse, the nonlinearity of disease progression gives an indication of the presence of periods with tumor dormancy $[8,9]$. Early micrometastatic foci, single cells, clusters of cells, or microscopic tumors can be restricted in growth over periods of time by inability to recruit blood vessels [10], by immunesurveillance [11], by cell cycle arrest [12], by tumor microenvironment (TME) interactions [13] as well as by iatrogenic depletion 
of growth stimulatory hormones in the case of ER+ breast cancer [14]. Interestingly, there are several experimental tumor models suggesting that dormant cancer can turn into rapidly progressing disease by growth systemic signals [8, $15,16]$. Moreover, systemic growth signals caused by tissue trauma and wound healing has been shown to initiate and synchronize growth of dormant micrometastases [17, 18]. Also clinical consequences of tissue trauma and wound healing have been discussed, as recently reviewed by Ceelen et al. [19]. Although controversial, in a series of clinical studies on human breast cancer, Demicheli et al. [20-22] suggest that the tissue trauma caused by the primary surgery alone is able to alter the growth kinetics of dormant micrometastases and reduce time to recurrence.

We hypothesize that activation of systemic growth signal cascade in breast cancer patients with dormant micrometastases might result in synchronized growth and thus the detection of multiple similar sized macrometastases at the time of first recurrence. Consequently, the detection of multiple similar sized metastases might serve as a marker of synchronized growth kinetics in these patients. In contrast, detection of solitary metastases or oligometastases with large size variation is more likely to occur when the metastases grow independently in the absence of a synchronizing signal. In the present study, we aimed to quantify size and number of metastatic lesions in relation to time between primary surgery and first relapse. We further hypothesized that growth of dormant micrometastases can be preceded by a synchronizing event like increased levels of wound healing associated growth factors following surgery or sudden withdrawal of anti-endocrine therapy. Moreover, we suggested that metastatic synchronization can be quantified by the standard deviation of size and number of metastases at time of first recurrence, as a marker of variation in the metastatic pattern. We focused on two clinically relevant candidate events that could lead to systemic synchronization of dormant micrometastases common to a majority of breast cancer patients; wound healing after primary surgery and cessation of endocrine adjuvant therapy.

\section{Methods}

The study base for this retrospective analysis consists of 209 consecutive patients treated for metastatic breast cancer between January 2005 and December 2009 at the Department of Oncology, Haukeland University Hospital, Norway. The hospital covers a population of 500,000, and all new diagnosed metastatic breast cancer patients in the population are referred to the regional center. All patients registered with an ICD-10 code for breast cancer (C 50.X) as well as one or more codes for metastases (C 77.X-C 79.X) were identified and all diagnoses were verified and validated in the patient records. Time to recurrence (TTR) was recorded as time between primary surgery and time of occurrence of first recorded metastasis. Patients with synchronous metastases and primaries, patients with evidence of metastatic disease within 2 months of surgery, patients that did not have their primary tumor removed, local recurrences, and patients with secondary (non-breast) cancers were excluded. Cases with measurable metastatic disease according to RECIST 1.1, modified by inclusion of both lytic and blastic bone lesions, were studied. Blastic bone metastases occur frequently in breast cancer and were regarded as evaluable for the purposes of this study. Thus, 180 patients were available for analyses of metastatic pattern.

At the time of first relapse, all patients underwent thorough staging with radiology, biochemistry, and clinical examination. Most patients were subjected to multiple radiology modalities like CT-scan, bone scan, MRI, ultrasound, and chest X-ray. All radiology and clinical tumor measurements were re-examined and the following variables were recorded; radiology modality, size of each metastatic lesion according to modified RECIST 1.1, number of metastases, and affected organs. Patients with more than 10 metastases were recorded as " $>10$ ". For each case, the standard deviation (SD) of the different sizes of the metastases was calculated. SD was used as a marker for variability in the metastatic pattern. Thus, a patient with multiple similar sized metastases at the time of first recurrence would present with a "low SD" (Fig. 1a), whereas a patient with, i.e., one large and two small metastases would have a "high SD" (Fig. 1b+c). Patients with solitary metastases $(n=41,23 \%)$ were excluded from analyses of SD. No patients underwent metastasectomy. To justify for the effect of tumor size on SD, we also examined the potential use of alternative metric measures of the metastases (SD divided by sum of diameters, SD divided by mean diameter, SD divided by the square root of the mean as well as SD divided by log mean) for their potential use as markers for synchronized growth.

The median value of SD was used as cut-off value and patients, were grouped as "low SD" and "high SD", accordingly. Associations between different categorical variables were assessed by Pearson's Chi-square test. Continuous variables not following the normal distribution were compared between two or more groups using the Mann-Whitney U tests. Univariate survival analyses were performed by the product-limit procedure (Kaplan-Meier method). Differences between categories were tested by the log-rank test. 


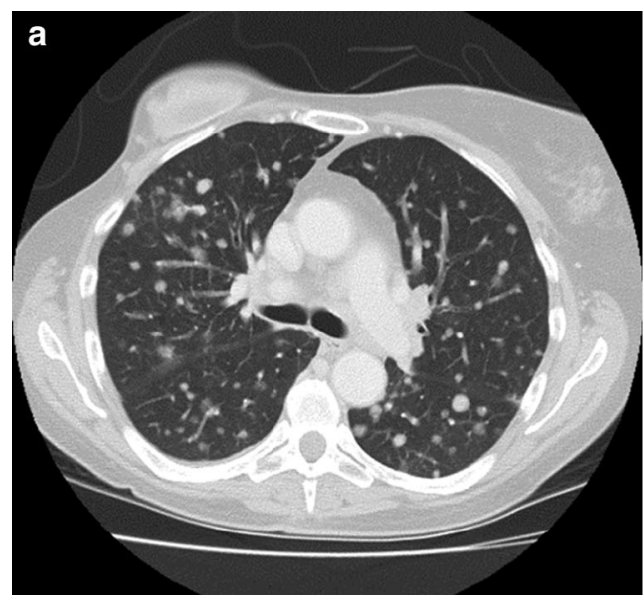

Fig. 1 Patient with multiple similar sized metastases at the time of first recurrence and with low standard deviation (SD) of size and number of metastatic lesions (a). Patient with one large liver

\section{Results}

The key demographics and pathologic and clinical characteristics of 180 patients recorded at the time of first recurrence are shown in Table 1. A majority of the patients were Stage 1-2 $(88 \%)$, ER + (77\%), Her2- $(77 \%)$. Bone- $(38 \%)$, lung- $(30 \%)$ and liver metastases $(23 \%)$ were the most frequent metastatic sites. For the majority of the patients (58\%), a CT-scan was the most appropriate modality for tumor size measurements. For patients with bone metastases, MRI (30\%) was the preferred modality, whereas ultrasound (lymph nodes) and x-ray (bone metastases and MRI contraindications) were used in some cases $(12 \%)$.

Median time to recurrence was 53 months (2.6-305), and no significant difference was present according to stage, primary tumor grade, or Her2 status in this population. ER negative patients (Log Rank $p<0.001)$ and younger patients (below median) (Log Rank $p=0.01$ ) had significantly shorter time to recurrence, median 28 versus 62 months and median 42 and 69, respectively. The annual hazard rate of recurrence for the whole study population is shown in Fig. 2.

Initially, we investigated the number and size of detected metastases in our patient population. The median number of lesions measured was 7 (mean 6). Still, some patients presented with more than 10 lesions and were recorded as " $>10$ ", accordingly. Forty-one ( $23 \%$ ) patients had only one measurable lesion at the time of first recurrence. Thus, SD was available in 142 patients. Median SD in the population was $5.4 \mathrm{~mm}$. Patients were grouped as "non-synchronized" if they had a SD above median or if they had only one measurable lesion, and as "synchronized" if they had a SD below median. Median sum of

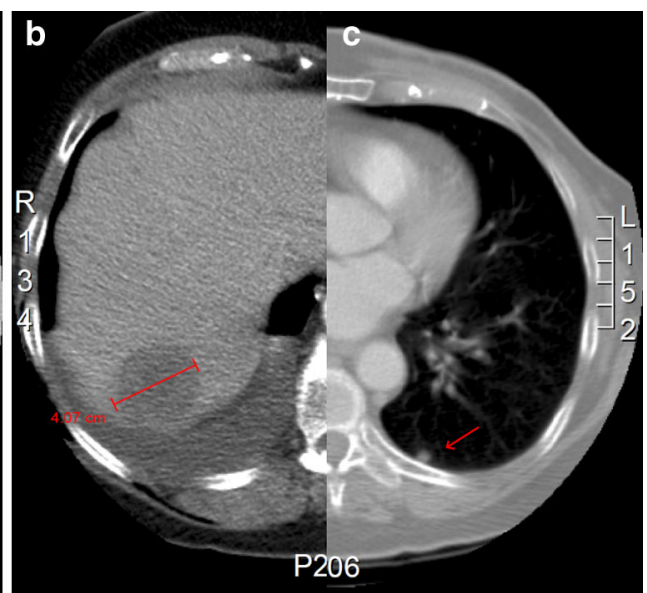

metastasis (red line) and two small metastases lung metastases at the time of the first recurrence (only one is shown here, red arrow) and with high $\mathrm{SD}(\mathbf{b}, \mathbf{c})$

diameters of metastatic lesions was $76 \mathrm{~mm}$ (10-697) (Table 2).

We then analyzed in each patient the SD of metastatic lesions in relation to time to recurrence. As illustrated in Fig. $3 a+b$, the mean SD of metastatic lesions seemed to be lower in the first 3 years after primary surgery, although this trend was not statistically significant. Moreover, as delayed recurrences as well as periods of tumor dormancy are more evident in the node negative patient [23, 24], we analyzed this group of patients separately. In this subset of patients, there was a significantly lower SD in patients who experienced early disease recurrence ( $\leq 3$ years) when compared to those with delayed recurrence $>3$ years (median 3.1 vs. 5.7, Mann-Whitney test, $p=0.018$ ) (Fig. $3 \mathrm{c}+$ d). Similarly, SD was significantly lower during the first three years after primary surgery in patients not receiving systemic adjuvant treatment (median 2.5 vs. 6.4 , Mann-Whitney test, $p=0.005$ ) (Fig $3 \mathrm{e}+\mathrm{f}$ ). There was no significant association between SD and time after surgery in patients receiving adjuvant systemic treatment.

Adjuvant endocrine treatment might affect the growth kinetics of dormant micrometastases. Consequently, we asked if a second drop in SD occurred at the time of withdrawal of endocrine treatment (5 years of tamoxifen or aromatase inhibitors). As expected, following the end of endocrine treatment at year 5, there was a second drop in $\mathrm{SD}$ (Fig 4a). When comparing the period just before end of endocrine treatment (year 4-5) with the period immediately after end of endocrine treatment (year 5-8) SD was significantly lower in the latter period (median 13.1 vs. 3.9, Mann-Whitney test, $p=0.021$, Fig $4 \mathrm{~b}$ ).

Low SD was significantly associated with low histological grade in primary tumors (Pearson Chi Square $p=0.002$ ), the absence of liver metastases (Pearson Chi 
Table 1 Patient characteristics

\begin{tabular}{|c|c|c|}
\hline & Number of patients & Percent \\
\hline \multicolumn{3}{|l|}{ Age } \\
\hline$<40$ & 6 & 3 \\
\hline $40-49$ & 25 & 14 \\
\hline $50-59$ & 43 & 24 \\
\hline $60-69$ & 48 & 27 \\
\hline$\geq 70$ & 58 & 32 \\
\hline \multicolumn{3}{|l|}{ Nodal status } \\
\hline pNO & 89 & 50 \\
\hline pN1 & 79 & 44 \\
\hline $\mathrm{pN} 2$ & 8 & 4 \\
\hline $\mathrm{pN} 3$ & 4 & 2 \\
\hline \multicolumn{3}{|l|}{ Tumor size } \\
\hline $\mathrm{T} 1(<2 \mathrm{~cm})$ & 74 & 41 \\
\hline T2 $(2-5 \mathrm{~cm})$ & 92 & 51 \\
\hline $\mathrm{T} 3(>5 \mathrm{~cm})$ & 12 & 7 \\
\hline $\mathrm{T} 4$ & 2 & 1 \\
\hline \multicolumn{3}{|l|}{ Stage } \\
\hline 1 & 47 & 26 \\
\hline $2 \mathrm{~A}$ & 63 & 35 \\
\hline $2 \mathrm{~B}$ & 49 & 27 \\
\hline $3 \mathrm{~A}$ & 15 & 9 \\
\hline 3B & 2 & 1 \\
\hline $3 \mathrm{C}$ & 4 & 2 \\
\hline \multicolumn{3}{|l|}{ Grade } \\
\hline 1 & 27 & 18 \\
\hline 2 & 74 & 49 \\
\hline 3 & 50 & 33 \\
\hline Missing & 29 & \\
\hline \multicolumn{3}{|l|}{ HR status } \\
\hline Neg & 41 & 23 \\
\hline Pos & 139 & 77 \\
\hline \multicolumn{3}{|l|}{ Her2 status } \\
\hline Neg & 80 & 80 \\
\hline Pos & 20 & 20 \\
\hline Missing & 80 & \\
\hline \multicolumn{3}{|c|}{ Adjuvant treatment } \\
\hline None & 62 & 35 \\
\hline Endocrine & 97 & 55 \\
\hline Chemotherapy & 62 & 35 \\
\hline \multicolumn{3}{|c|}{ Radiology modality $^{\mathrm{a}}$} \\
\hline CT-scan & 104 & 58 \\
\hline MRI & 55 & 30 \\
\hline Other $^{b}$ & 21 & 12 \\
\hline \multicolumn{3}{|l|}{ Metastatic site } \\
\hline Bone & 68 & 38 \\
\hline Lymph nodes & 31 & 17 \\
\hline Lung & 54 & 30 \\
\hline Liver & 41 & 23 \\
\hline
\end{tabular}

Table 1 continued

\begin{tabular}{lcc}
\hline & Number of patients & Percent \\
\hline Brain & 9 & 5 \\
Other & 21 & 12 \\
\hline
\end{tabular}

Key demographic and pathological characteristics including age, nodal status, tumor size, stage, grade, HR status, and Her2 status at the time of primary surgery in 180 patients recorded with metastases from breast cancer during 2005-2009 at Haukeland University Hospital, Norway

${ }^{\text {a }}$ Refers to the radiology modality used for the analysis of metastases number and size

${ }^{\mathrm{b}}$ Ultrasound, chest x-ray, clinical measurement (caliper)

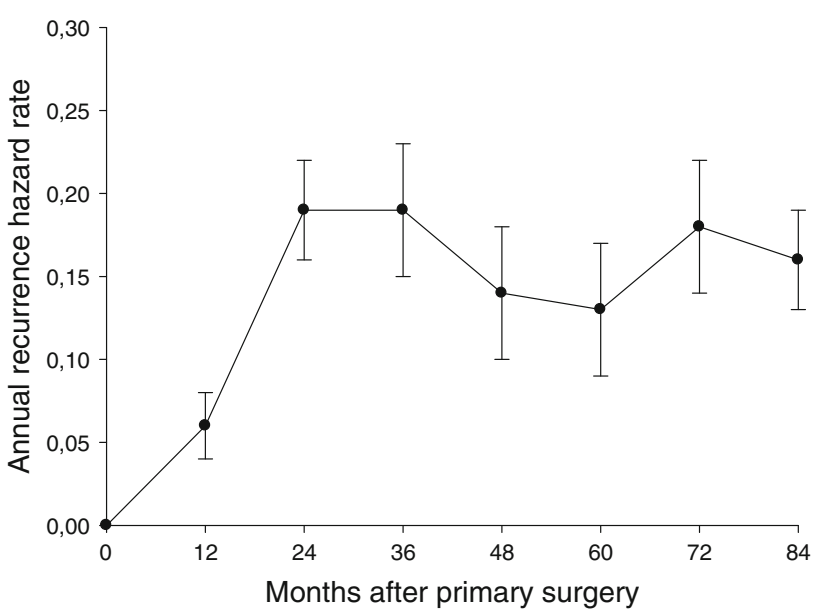

Fig. 2 Annual recurrence hazard rate $( \pm$ SE) in 180 patients recorded with metastatic breast cancer at Haukeland university Hospital during 2005-2009

Table 2 Metastatic pattern

\begin{tabular}{lllc}
\hline & Median & Mean & Min-max \\
\hline Number of lesions counted $^{\mathrm{a}}$ & 7 & 6 & $1->10$ \\
$\begin{array}{l}\sum \text { diameter of lesions per case (mm) } \\
\text { Standard deviation of lesions }\end{array}$ & 5.4 & 89 & $10-697$ \\
$\quad$ per case (mm) & 53 & 69 & $0-58$ \\
Time to recurrence (months) & $2.6-305$ \\
\hline
\end{tabular}

Analysis of metastatic pattern at first recurrence in 180 cases of metastatic breast cancer treated at Haukeland University Hospital, Norway. Tumor measurements are in accordance with RECIST 1.1

${ }^{\mathrm{a}}$ If $>10$ lesions, $n=10$

Square $p=0.001$ ), and the presence of lung metastases (Pearson Chi Square $p=0.02$ ). No statistically significant association was found between SD and ER status, Her2 status, radiology modality, nodal status, or stage. Other metric measures of the metastases (see methods) did not give significant information in addition to the analyses of SD. 
a
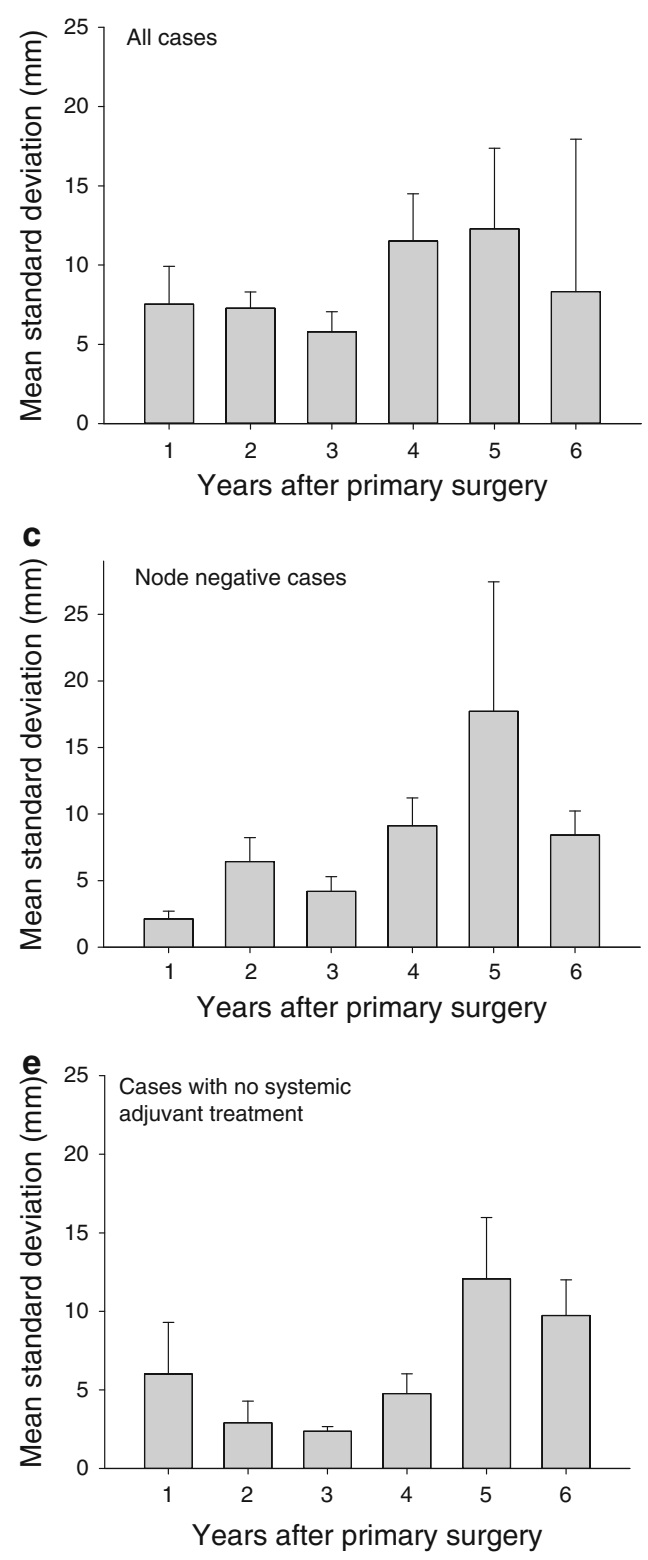

Fig. 3 Metastatic pattern in 180 breast cancer patients. The plots show the mean of the standard deviation (SD) of size and number of metastases in each patient at first recurrence $( \pm$ SE) according to time after surgery. a All cases. b Box plot of mean SD according to early

Finally, in the analyses of overall survival between time of first recurrence and death, significantly increased survival was present in $\mathrm{ER}+$ cases (Log Rank $p=0.05$ ), Her2 positive cases (Log Rank $p=0.008$ ) as well as in cases with low tumor load as measured by sum of diameters of metastatic lesions at time of first recurrence ( $\log$ Rank $p=0.001$ ). No survival differences were present for $\mathrm{SD}$, liver metastases, lung metastases, stage at primary diagnosis, or time between primary diagnosis and recurrence.

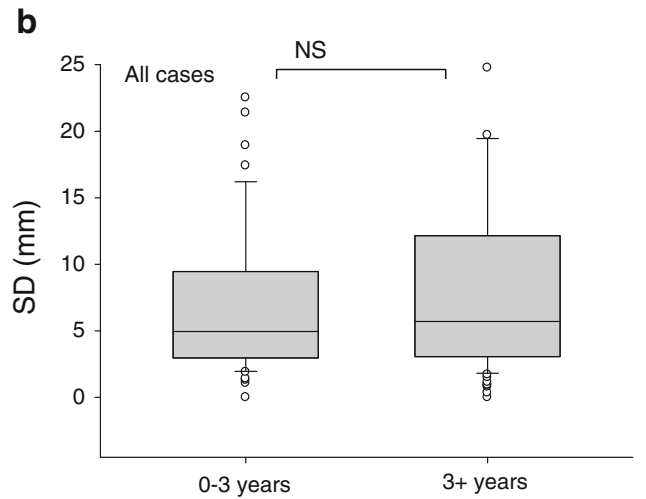

d
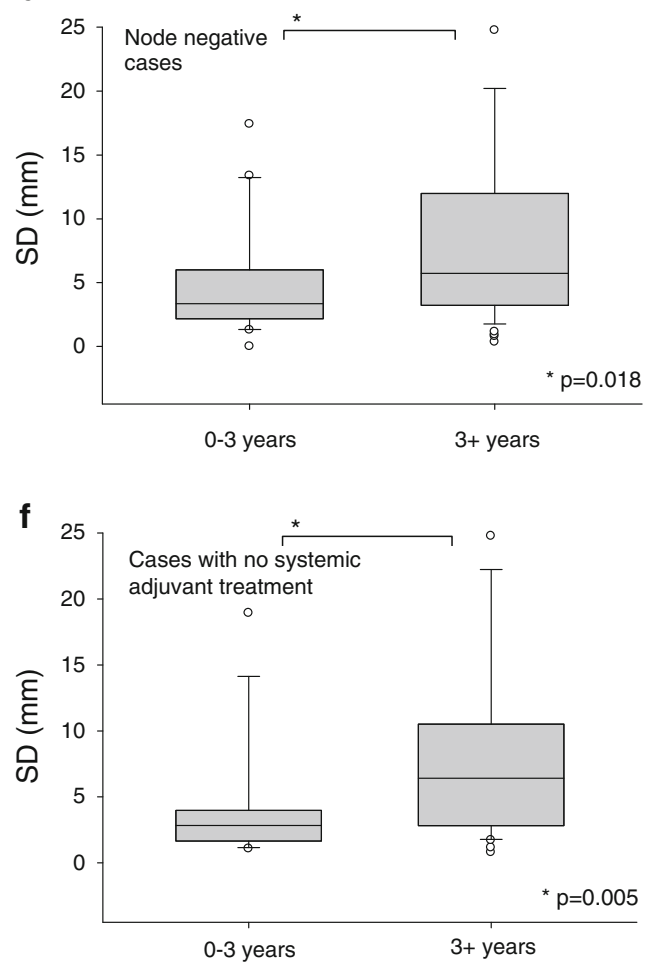

recurrences ( $0-3$ years) versus late recurrences $(3+$ years), all cases. c, d Node negative cases e, f Cases with no systemic adjuvant treatment. *Mann-Whitney test

\section{Discussion}

This study was initiated following the clinical observation of variation in metastatic patterns in patients referred to our ward at the time of first metastatic recurrence from breast cancer. Whereas some patients presented with solitary or oligometastases of varying size, other patients showed multiple similar sized metastases in one or more organs. We further observed that patients in the latter category were frequently diagnosed with metastatic disease shortly 


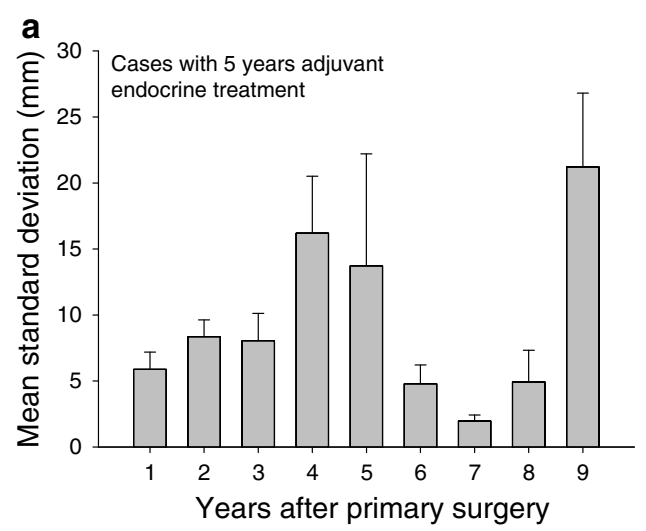

Fig. 4 Metastatic pattern in the subgroup of breast cancer patients treated with adjuvant endocrine therapy. a Mean of the standard deviation (SD) of size and number of metastases in each patient at

after primary surgery, shortly after delayed breast reconstruction, or shortly after end of adjuvant endocrine treatment. Delayed recurrence of breast cancer metastases is frequently observed in patients with estrogen receptor (ER) positive disease in particular [5]. An annual recurrence rate of $2 \%$, for as long as 15 years even after 5 years of tamoxifen [25] or aromatase inhibitors [26], prevents these patients from considering themselves as cured even for decades.

The prominent variation in time between primary surgery and first relapse in breast cancer suggests that there is a great heterogeneity among patients or in the inherent biology of the tumor cells per se. In some cases, a steady growth of metastases and a constant risk of relapse can be inferred by modeling the time of primary tumor detection in relation to the time of relapse as well as the size and number of metastases [27]. In addition, tumor dormancy also in primary tumors is frequently found in the breast, the prostate, and the thyroid gland of undiagnosed patients in various autopsy materials [28], further supporting the existence of growth inhibiting mechanisms or the absence of growth stimulating signals.

In spite of otherwise favorable prognosis when compared with node positive $(\mathrm{N}+)$ patients, some node negative (N0) patients do relapse with metastatic tumor growth. In large patient series, the relapses observed in the node negative patients also show a tendency of occurring later when compared with node positive patients [23, 24]. Even tiny tumors might eventually recur at distant sites in spite of radical surgery at the primary stage. The station by station model of breast cancer progression put forward by Halsted over a century ago [29] followed by large and mutilating ultra-radical surgery procedures has been replaced by less invasive methods [30-33]. Recently, also the value of lymph node dissection even in sentinel node positive patients has been challenged [34]. The multimodal

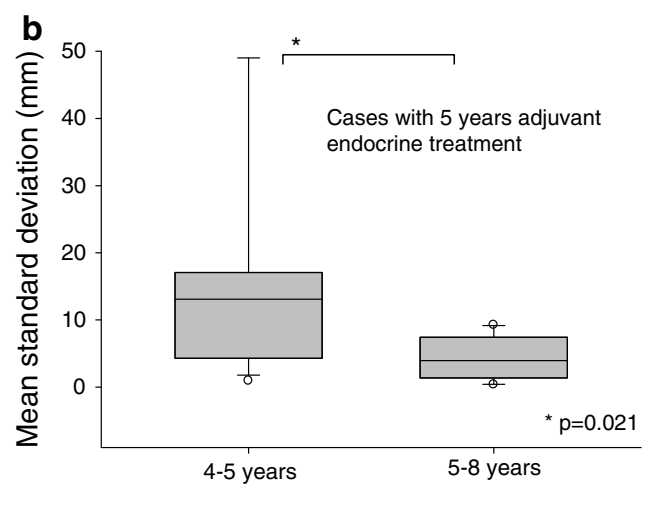

first recurrence ( \pm SE) according to time after surgery. b Box plot of mean SD compared between the time before versus after cessation of adjuvant endocrine treatment. *Mann-Whitney test

approaches including limited surgery with immediate reconstruction, limited irradiation, and effective systemic adjuvant therapy, presently give the best total outcome regarding both survival and quality of life. Nevertheless, in spite of all the recent achievements in the treatment of primary breast cancer, about 10 percent of patients eventually relapse [35]. Even if the concept of tumor dormancy in breast cancer seems to be well established, several controversies concerning the clinical impact exist [36]. Little is known about what mechanisms control dormancy in human micrometastatic disease, and even more important; what physiologic processes can cause the suspension of dormancy and thereby fatal disease relapse. The Gompertzian model of human breast cancer growth as discussed by Norton [37], or more complicated models as suggested by Speer et al. [38], can predict progression of the unperturbed primary tumor and are widely applied in the planning of adjuvant trials. Several mathematical models have been applied to describe different relapse scenarios with regard to time, size, and number of metastases [27, 37, 39]. Still, the lack of knowledge on the mechanisms controlling tumor dormancy and tumor growth spurts renders these models as crude approximations when it comes to predicting relapse in individual patients. The typically highly variable remission periods between resection and relapse in breast cancer patients are inexplicable by continuous growth of metastases [40-42] and imply some degree of growth restriction of occult micrometastases.

In theory, assuming a situation with a period of tumor dormancy before, during or after primary surgery, the likelihood of finding a solitary metastasis at the time of first recurrence is statistically higher than finding multiple metastases. This assumption is valid only if there is no synchronized internal clock in the metastatic tumor cells or no systemic signal to synchronize metastatic growth. Still, in the clinic, we frequently observe patients with multiple 
similar sized metastases at first recurrence even many years after removal of the primary tumor. These observations support the concept that there might be a systemic event simultaneously breaking the dormant state of micrometastases. In addition to immunosuppression [11] and hormone deprival [14], it has been suggested that wound healing following the primary surgery might be one such synchronizing signal, by turning on the angiogenic switch in dormant micrometastases and thereby activating angiogenesis [16-18]. The frequently observed peak in the hazard ratio of relapse around 18 months, independent of primary tumor stage $[20,25,43]$, has been attributed to the systemic response to primary surgery of breast tumors [44].

In order to find clinical support for a possible association between time of primary surgery and synchronized growth of dormant micrometastases, we studied the metastatic pattern in 180 breast cancer patients at the time of first recurrence. We established the SD of the measured sizes of the metastases as a potential marker for synchronized growth. It is a possible drawback in our material that our patients, in most cases, presented with symptoms or biochemical alterations before the diagnosis of recurrence was established. In Norway, there is no requirement for routine radiological examinations during follow-up. Thus, our data does not give exact information on how long the lesions might have been detectable by radiology ahead of diagnosis, nor of the growth rate. There is a possibility that the power of SD as a marker for synchronized growth is diluted by this weakness. Still, as a marker to identify cases with low variation versus high variation in number and size of metastases (i.e., synchronized vs. non-synchronized), SD was superior to other metric estimates (see methods) by computational simulation, especially when a Gompertzian growth pattern was assumed. Nevertheless, there is a possibility that the size dependency of SD makes direct comparison between the very small and the very large metastatic lesions inaccurate. To our knowledge, this approach has not been previously reported, and thus needs to be confirmed in separate datasets.

We found that the SD was lower in early recurrences (0-3 years after surgery), and this difference was statistically significant in node negative patients. The difference between the node negative and the node positive patients might be due to the difference in the overall prognosis. In node positive patients, the micrometastatic spread is frequently more advanced at the time of primary surgery and the growth into macrometastases might already have been initiated. In contrast, regarding the node negative patients, our results indicate that the dormancy of systemic micrometastases seems to be more susceptible to a systemic synchronizing growth signal. This is in line with the observed delayed recurrences in node negative patients in large patient materials [23, 24]. Sixty-five percent of our patients received systemic adjuvant treatment after primary surgery. The sole intention of this treatment is to prevent or at least delay growth of micrometastases, and this effect was also reflected in a significantly lower SD in early recurrences observed in cases not given adjuvant treatment. This finding might suggest that adjuvant systemic treatment prevents the effect of the synchronizing systemic signal on the tumor cells during the time immediately after surgery. Importantly, delayed initiation of adjuvant chemotherapy has recently been shown to be associated with significantly worse outcome [45], further underlining the importance of the time window immediately following the surgical procedure. We also cannot rule out the possibility that the association between SD and time to recurrence found in node negative cases is, in part, due to the increased use of adjuvant treatment in node positive cases. As expected, there was a second drop in SD directly after end of adjuvant endocrine treatment in ER + patients. From this, we might infer that the removal of the estrogen receptor or aromatase inhibitors acts as a second systemic signal to synchronize growth of occult micrometastases kept dormant during estrogen deprival. This expected finding also serves as an internal control for the utility of $\mathrm{SD}$ as a marker of synchronized growth. In comparison to $\mathrm{ER}-$, the ER+ population recurs later [1], and this was also the case in our study. An alternative explanation for the delayed relapse and prolonged dormant state of the slow growing ER+ tumors could be the requirement of an spontaneous enabling sub-clonal evolution in these cells [46], which would occur independently in individual cells over time. The subsequent macrometastases are then likely to be asynchronous. Still, there was no significant association between ER status and SD. This suggests that synchronization occurs at a similar rate in ER positive and negative patients. Low SD correlated with low histologic grade in the primary tumors and suggests that synchronized metastatic growth is more frequent in cases with lower tumor heterogeneity. Still, no significant association between histologic grade and time to recurrence was found. Synchronized growth, quantified by low SD, showed an inverse association in lung metastases and liver metastases. Whereas in the lung, the SD was found to be lower when compared with other sites, SD was significantly higher in the liver, suggesting a different growth dynamic between different organs. Still, most of our patients presented with lesions at multiple sites. In a recent report by Cummings et al. [47] 197 autopsies on patients that died of breast cancer were examined in detail. Of a total of 150 patients, the 46 patients who underwent surgical treatment of the primary tumor were significantly more likely to develop liver metastases, suggesting a role of acute wound healing 
after surgery in activating dormant micrometastases in the liver. Similar findings have also been reported by others [48]. Experimental studies have also reported the role of post-surgical wound healing in stimulating growth of liver metastases [16]. Levels of wound healing associated growth factors like Vascular Endothelial Growth Factor show great heterogeneity between patients and also between peripheral blood and locally at the wound site [49]. Studies also show that levels of angiogenesis inhibitors might change following surgery or radiation therapy of the primary tumor $[50,51]$.

The effect of surgery on macrometastases has been an unresolved issue addressed in multiple retrospective trials studying the impact of removal of the breast in patients with stage IV disease at presentation [52, 53]. Still, several of these trials have been significantly biased based on inclusion criteria. Nevertheless, surgical treatment in patients with synchronous metastases is frequently recommended to increase local control, although overall survival benefit remains to be proven [53]. Recently, a clinical study on 350 women with stage IV disease at presentation, randomized between surgical removal of primary tumor and axillary lymph nodes and systemic therapy, or systemic therapy alone, was presented by Badwe et al. [54]. Although a significant increase in local control was found, the distant site progression free survival was significantly decreased after surgery. Thus, suggesting a detrimental effect of the surgical procedure, as put forward by Fisher et al. [55]. No difference in overall survival was found.

In conclusion, our results identify the standard deviation of number and size of metastases at first recurrence as a marker of synchronized growth of breast cancer metastases. Furthermore, significantly lower SD in early recurrences in node negative patients and patients not given adjuvant systemic treatment suggests a link between the surgical procedure and early synchronized metastatic growth, which might be inhibited by systemic adjuvant treatment. Further research that aim to identify the systemic growth signals caused by surgery and wound healing, might open additional therapeutic opportunities during the time window around or immediately after surgical intervention.

Acknowledgments The study was supported by Grants from The Norwegian Cancer Association and Helse Vest.

Conflict of interest The authors have declared no conflict of interests associated with this study.

Open Access This article is distributed under the terms of the Creative Commons Attribution Noncommercial License which permits any noncommercial use, distribution, and reproduction in any medium, provided the original author(s) and the source are credited.

\section{References}

1. Brewster AM, Hortobagyi GN, Broglio KR, Kau SW, SantaMaria CA, Arun B, Buzdar AU, Booser DJ, Valero V, Bondy M, Esteva FJ (2008) Residual risk of breast cancer recurrence 5 years after adjuvant therapy. $J$ Natl Cancer Inst 100(16):1179-1183. doi:10.1093/jnci/djn233

2. Demicheli R, Biganzoli E, Ardoino I, Boracchi P, Coradini D, Greco M, Moliterni A, Zambetti M, Valagussa P, Gukas ID, Bonadonna G (2010) Recurrence and mortality dynamics for breast cancer patients undergoing mastectomy according to estrogen receptor status: different mortality but similar recurrence. Cancer Sci 101(3):826-830. doi:10.1111/j.1349-7006. 2009.01472.x

3. Ribelles N, Perez-Villa L, Jerez JM, Pajares B, Vicioso L, Jimenez B, de Luque V, Franco L, Gallego E, Marquez A, Alvarez M, Sanchez-Munoz A, Perez-Rivas L, Alba E (2013) Pattern of recurrence of early breast cancer is different according to intrinsic subtype and proliferation index. Breast Cancer Res 15(5):R98. doi:10.1186/bcr3559

4. Voduc KD, Cheang MC, Tyldesley S, Gelmon K, Nielsen TO, Kennecke H (2010) Breast cancer subtypes and the risk of local and regional relapse. J Clin Oncol 28(10):1684-1691. doi:10. 1200/JCO.2009.24.9284

5. Sestak I, Dowsett M, Zabaglo L, Lopez-Knowles E, Ferree S, Cowens JW, Cuzick J (2013) Factors predicting late recurrence for estrogen receptor-positive breast cancer. J Natl Cancer Inst 105(19):1504-1511. doi:10.1093/jnci/djt244

6. Esserman LJ, Moore DH, Tsing PJ, Chu PW, Yau C, Ozanne E, Chung RE, Tandon VJ, Park JW, Baehner FL, Kreps S, Tutt AN, Gillett CE, Benz CC (2011) Biologic markers determine both the risk and the timing of recurrence in breast cancer. Breast Cancer Res Treat 129(2):607-616. doi:10.1007/s10549-011-1564-5

7. Kennecke H, Yerushalmi R, Woods R, Cheang MC, Voduc D, Speers CH, Nielsen TO, Gelmon K (2010) Metastatic behavior of breast cancer subtypes. J Clin Oncol 28(20):3271-3277. doi:10. 1200/JCO.2009.25.9820

8. Goss P, Allan AL, Rodenhiser DI, Foster PJ, Chambers AF (2008) New clinical and experimental approaches for studying tumor dormancy: does tumor dormancy offer a therapeutic target? APMIS 116(7-8):552-568. doi:10.1111/j.1600-0463.2008. 001059.x

9. Hanin L (2013) Seeing the invisible: how mathematical models uncover tumor dormancy, reconstruct the natural history of cancer, and assess the effects of treatment. Adv Exp Med Biol 734:261-282. doi:10.1007/978-1-4614-1445-2_12

10. Holmgren L, O'Reilly MS, Folkman J (1995) Dormancy of micrometastases: balanced proliferation and apoptosis in the presence of angiogenesis suppression. Nat Med 1(2):149-153

11. Koebel CM, Vermi W, Swann JB, Zerafa N, Rodig SJ, Old LJ, Smyth MJ, Schreiber RD (2007) Adaptive immunity maintains occult cancer in an equilibrium state. Nature 450(7171):903-907. doi:10.1038/nature06309

12. Ranganathan AC, Adam AP, Aguirre-Ghiso JA (2006) Opposing roles of mitogenic and stress signaling pathways in the induction of cancer dormancy. Cell Cycle 5(16):1799-1807

13. Sosa MS, Bragado P, Debnath J, Aguirre-Ghiso JA (2013) Regulation of tumor cell dormancy by tissue microenvironments and autophagy. Adv Exp Med Biol 734:73-89. doi:10.1007/978-14614-1445-2_5

14. Davies C, Pan H, Godwin J, Gray R, Arriagada R, Raina V, Abraham M, Medeiros Alencar VH, Badran A, Bonfill X, Bradbury J, Clarke M, Collins R, Davis SR, Delmestri A, Forbes JF, Haddad P, Hou MF, Inbar M, Khaled H, Kielanowska J, Kwan WH, Mathew BS, Mittra I, Muller B, Nicolucci A, Peralta 
O, Pernas F, Petruzelka L, Pienkowski T, Radhika R, Rajan B, Rubach MT, Tort S, Urrutia G, Valentini M, Wang Y, Peto R, Adjuvant Tamoxifen: Longer Against Shorter Collaborative G (2013) Long-term effects of continuing adjuvant tamoxifen to 10 years versus stopping at 5 years after diagnosis of oestrogen receptor-positive breast cancer: ATLAS, a randomised trial. Lancet 381(9869):805-816. doi:10.1016/S0140-6736(12)61963-1

15. Straume O, Shimamura T, Lampa MJ, Carretero J, Oyan AM, Jia D, Borgman CL, Soucheray M, Downing SR, Short SM, Kang SY, Wang S, Chen L, Collett K, Bachmann I, Wong KK, Shapiro GI, Kalland KH, Folkman J, Watnick RS, Akslen LA, Naumov GN (2012) Suppression of heat shock protein 27 induces longterm dormancy in human breast cancer. Proc Natl Acad Sci USA 109(22):8699-8704. doi:10.1073/pnas.1017909109

16. Murthy SM, Goldschmidt RA, Rao LN, Ammirati M, Buchmann T, Scanlon EF (1989) The influence of surgical trauma on experimental metastasis. Cancer 64(10):2035-2044

17. Gill M, Dias S, Hattori K, Rivera ML, Hicklin D, Witte L, Girardi L, Yurt R, Himel H, Rafii S (2001) Vascular trauma induces rapid but transient mobilization of VEGFR2(+) AC133(+) endothelial precursor cells. Circ Res 88(2):167-174

18. Indraccolo S, Stievano L, Minuzzo S, Tosello V, Esposito G, Piovan E, Zamarchi R, Chieco-Bianchi L, Amadori A (2006) Interruption of tumor dormancy by a transient angiogenic burst within the tumor microenvironment. Proc Natl Acad Sci USA 103(11):4216-4221

19. Ceelen W, Pattyn P, Mareel M (2014) Surgery, wound healing, and metastasis: recent insights and clinical implications. Crit Rev Oncol Hematol 89(1):16-26. doi:10.1016/j.critrevonc.2013.07. 008

20. Demicheli R, Abbattista A, Miceli R, Valagussa P, Bonadonna G (1996) Time distribution of the recurrence risk for breast cancer patients undergoing mastectomy: further support about the concept of tumor dormancy. Breast Cancer Res Treat 41(2):177185

21. Demicheli R, Valagussa P, Bonadonna G (2001) Does surgery modify growth kinetics of breast cancer micrometastases? $\mathrm{Br} \mathrm{J}$ Cancer 85(4):490-492. doi:10.1054/bjoc.2001.1969

22. Demicheli R, Ardoino I, Boracchi P, Coradini D, Agresti R, Ferraris C, Gennaro M, Hrushesky WJ, Biganzoli E (2010) Recurrence and mortality according to estrogen receptor status for breast cancer patients undergoing conservative surgery. Ipsilateral breast tumour recurrence dynamics provides clues for tumour biology within the residual breast. BMC Cancer 10:656. doi:10.1186/1471-2407-10-656

23. Singletary SE, Allred C, Ashley P, Bassett LW, Berry D, Bland KI, Borgen PI, Clark G, Edge SB, Hayes DF, Hughes LL, Hutter RV, Morrow M, Page DL, Recht A, Theriault RL, Thor A, Weaver DL, Wieand HS, Greene FL (2002) Revision of the American Joint Committee on Cancer staging system for breast cancer. J Clin Oncol 20(17):3628-3636

24. Carter CL, Allen C, Henson DE (1989) Relation of tumor size, lymph node status, and survival in 24,740 breast cancer cases. Cancer 63(1):181-187

25. Saphner T, Tormey DC, Gray R (1996) Annual hazard rates of recurrence for breast cancer after primary therapy. J Clin Oncol 14(10):2738-2746

26. Cuzick J, Sestak I, Baum M, Buzdar A, Howell A, Dowsett M, Forbes JF, Investigators AL (2010) Effect of anastrozole and tamoxifen as adjuvant treatment for early-stage breast cancer: 10-year analysis of the ATAC trial. Lancet Oncol 11(12):1135-1141. doi:10.1016/S1470-2045(10)70257-6

27. Willis L, Graham TA, Alarcon T, Alison MR, Tomlinson IP, Page KM (2013) What can be learnt about disease progression in breast cancer dormancy from relapse data? PLoS ONE 8(5):e62320. doi:10.1371/journal.pone.0062320
28. Naumov GN, Folkman J, Straume O, Akslen LA (2008) Tumorvascular interactions and tumor dormancy. Apmis 116(7-8):569-585

29. Halsted WS (1907) I. the results of radical operations for the cure of carcinoma of the breast. Ann Surg 46(1):1-19

30. Fisher B, Montague E, Redmond C, Barton B, Borland D, Fisher ER, Deutsch M, Schwarz G, Margolese R, Donegan W, Volk H, Konvolinka C, Cohn I Jr, Lesnick G, Cruz AB, Lawrence W, Nealon T, Butcher H, Lawton R (1977) Comparison of radical mastectomy with alternative treatments for primary breast cancer. A first report of results from a prospective randomized clinical trial. Cancer 39(6):2827-2839

31. Poggi MM, Danforth DN, Sciuto LC, Smith SL, Steinberg SM, Liewehr DJ, Menard C, Lippman ME, Lichter AS, Altemus RM (2003) Eighteen-year results in the treatment of early breast carcinoma with mastectomy versus breast conservation therapy: the National Cancer Institute Randomized Trial. Cancer 98(4):697-702. doi:10.1002/cncr.11580

32. Agarwal S, Pappas L, Neumayer L, Kokeny K, Agarwal J (2014) Effect of breast conservation therapy versus mastectomy on disease-specific survival for early-stage breast cancer. JAMA surg. doi:10.1001/jamasurg.2013.3049

33. Fisher B (1999) From Halsted to prevention and beyond: advances in the management of breast cancer during the twentieth century. Eur J Cancer 35(14):1963-1973

34. Giuliano AE, Hunt KK, Ballman KV, Beitsch PD, Whitworth PW, Blumencranz PW, Leitch AM, Saha S, McCall LM, Morrow M (2011) Axillary dissection vs no axillary dissection in women with invasive breast cancer and sentinel node metastasis: a randomized clinical trial. JAMA 305(6):569-575. doi:10.1001/jama. 2011.90

35. Walters S, Maringe C, Butler J, Rachet B, Barrett-Lee P, Bergh J, Boyages J, Christiansen P, Lee M, Warnberg F, Allemani C, Engholm G, Fornander T, Gjerstorff ML, Johannesen TB, Lawrence G, McGahan CE, Middleton R, Steward J, Tracey E, Turner D, Richards MA, Coleman MP, Group IMW (2013) Breast cancer survival and stage at diagnosis in Australia, Canada, Denmark, Norway, Sweden and the UK, 2000-2007: a population-based study. Br J Cancer 108(5):1195-1208. doi:10.1038/bjc.2013.6

36. Uhr JW, Pantel K (2011) Controversies in clinical cancer dormancy. Proc Natl Acad Sci USA 108(30):12396-12400. doi:10. 1073/pnas.1106613108

37. Norton L (1988) A gompertzian model of human breast cancer growth. Cancer Res 48(24 Pt 1):7067-7071

38. Speer JF, Petrosky VE, Retsky MW, Wardwell RH (1984) A stochastic numerical model of breast cancer growth that simulates clinical data. Cancer Res 44(9):4124-4130

39. Withers HR, Lee SP (2006) Modeling growth kinetics and statistical distribution of oligometastases. Semin Radiat Oncol 16(2):111-119

40. Aguirre-Ghiso JA (2007) Models, mechanisms and clinical evidence for cancer dormancy. Nat Rev Cancer 7(11):834-846. doi: $10.1038 / \mathrm{nrc} 2256$

41. Chambers AF, Goss PE (2008) Putative growth characteristics of micrometastatic breast cancer. Breast Cancer Res 10(6):114. doi:10.1186/bcr2197

42. Meltzer A (1990) Dormancy and breast cancer. J Surg Oncol 43(3): 181-188

43. Gao F, Tan SB, Machin D, Wong NS (2007) Confirmation of double-peaked time distribution of mortality among Asian breast cancer patients in a population-based study. Breast Cancer Res 9(2):R21

44. Retsky MW, Demicheli R, Hrushesky WJ, Baum M, Gukas ID (2008) Dormancy and surgery-driven escape from dormancy help explain some clinical features of breast cancer. APMIS 116(7-8):730-741. doi:10.1111/j.1600-0463.2008.00990.x 
45. Gagliato Dde M, Gonzalez-Angulo AM, Lei X, Theriault RL, Giordano SH, Valero V, Hortobagyi GN, Chavez-Macgregor M (2014) Clinical impact of delaying initiation of adjuvant chemotherapy in patients with breast cancer. J Clin Oncol 32(8):735-744. doi:10.1200/JCO.2013.49.7693

46. Torres L, Ribeiro FR, Pandis N, Andersen JA, Heim S, Teixeira MR (2007) Intratumor genomic heterogeneity in breast cancer with clonal divergence between primary carcinomas and lymph node metastases. Breast Cancer Res Treat 102(2):143-155. doi:10.1007/s10549-006-9317-6

47. Cummings MC, Simpson PT, Reid LE, Jayanthan J, Skerman J, Song S, McCart Reed AE, Kutasovic JR, Morey AL, Marquart L, O'Rourke P, Lakhani SR (2013) Metastatic progression of breast cancer: insights from 50 years of autopsies. J Pathol. doi:10.1002/ path. 4288

48. Barista I, Baltali E, Gullu IH, Guler N, Celik I, Saracbasi O, Tekuzman G, Kars A, Ozisik Y, Ruacan S, Atahan IL, Firat D (1996) Factors influencing the distribution of metastases and survival in metastatic breast carcinoma. Am $\mathrm{J}$ Clin Oncol 19(6):569-573

49. Hormbrey E, Han C, Roberts A, McGrouther DA, Harris AL (2003) The relationship of human wound vascular endothelial growth factor (VEGF) after breast cancer surgery to circulating VEGF and angiogenesis. Clin Cancer Res 9(12):4332-4339

50. O'Reilly MS, Holmgren L, Shing Y, Chen C, Rosenthal RA, Moses M, Lane WS, Cao Y, Sage EH, Folkman J (1994)
Angiostatin: a novel angiogenesis inhibitor that mediates the suppression of metastases by a Lewis lung carcinoma. Cell 79(2):315-328

51. Camphausen K, Moses MA, Beecken WD, Khan MK, Folkman J, O'Reilly MS (2001) Radiation therapy to a primary tumor accelerates metastatic growth in mice. Cancer Res 61(5):2207-2211

52. Petrelli F, Barni S (2012) Surgery of primary tumors in stage IV breast cancer: an updated meta-analysis of published studies with meta-regression. Med Oncol 29(5):3282-3290. doi:10.1007/ s12032-012-0310-0

53. Dominici L, Najita J, Hughes M, Niland J, Marcom P, Wong YN, Carter B, Javid S, Edge S, Burstein H, Golshan M (2011) Surgery of the primary tumor does not improve survival in stage IV breast cancer. Breast Cancer Res Treat 129(2):459-465. doi:10.1007/ s10549-011-1648-2

54. Badwe R (2013) Surgical removal of primary tumor and axillary lymph nodes in women with metastatic breast cancer at first presentation: a randomized controlled trial. In: SABCS, San Antonio

55. Fisher B, Gunduz N, Saffer EA (1983) Influence of the interval between primary tumor removal and chemotherapy on kinetics and growth of metastases. Cancer Res 43(4):1488-1492 